\title{
MEMORIA Y PATRIMONIO EN RIESGO: LOS ENCAUCHADOS Y EL CONTRABANDO DE AGUARDIENTE EN BAÑOS (CUENCA-ECUADOR)
}

\author{
MEMORY AND HERITAGE AT RISK: THE ENCAUCHADOS \\ AND LIQUOR CONTRABAND IN BANNOS (CUENCA-ECUADOR)
}

Miguel Ángel Novillo Verdugo* y Elsa Rosario Sinchi Lojano**

\begin{abstract}
Baños es una parroquia rural de Cuenca (Ecuador) culturalmente diversa, donde, de forma paulatina, sus prácticas y tradiciones se transforman o desaparecen, generando olvido, pérdida y ausencia de identidad. De esta manera, es necesario registrar y traer a la actualidad ciertos hechos que forman parte de la historia local, partiendo del estudio de los denominados encauchados (ponchos, zamarros, perras ${ }^{1}$ ) y su relación directa con el contrabando de aguardiente a mediados del siglo XX. Para tal efecto, se realizaron entrevistas a los actores de estas actividades, quienes por medio de la memoria y la oralidad nos dan cuenta de ese pasado.
\end{abstract}

Palabras claves: Testimonio oral, identidad, memoria, encauchados, contrabando, patrimonio.

Baños is a culturally diverse rural parish of Cuenca (Ecuador) where, gradually, its practices and traditions are changing or disappearing, generating oblivion, loss, and absence of identity. Thus, it is necessary to register and bring to the present some events that are part of the local history, starting from the study of the so-called 'encauchados' (ponchos, zamarros, perras) and their direct relationship with liquor contraband around the middle of the 20th century. For such purpose, interviews were carried out with the actors of these activities, who give us an account of the past through memory and oral tradition.

Key words: Oral testimony, identity, memory, encauchados, contraband, heritage.

\section{Introducción}

En el área rural de la ciudad de Cuenca (Ecuador) se localiza la parroquia de Baños, que es reconocida por su historia colonial minera, por el aprovechamiento turístico de las aguas termales y por la arraigada devoción a la Virgen de Guadalupe (regionalmente es una de las más prestigiosas). De igual manera, Baños representa un espacio de manifestaciones culturales, como elaboración de encauchados y pirotecnia, establecimiento de bandas de pueblo (música), expresiones de espiritualidad y relaciones de priostazgo, variedad gastronómica y una rica tradición oral, entre otras manifestaciones.

Para la comprensión de la dinámica social y cultural de un pueblo, es necesario que confluyan varios elementos que intentan clarificar y entender las acciones de la colectividad, en un medio general, teniendo en consideración contexto y momento histórico donde se desarrollan los mismos. De esta forma, la ciencia histórica transita por un complejo y difícil camino de adversidades, donde intereses individuales priman por sobre los colectivos. Se pretende, en muchas ocasiones, esconder realidades pasadas que resultan ignominiosas en el presente, pero que, en conjunto, representan el sentir y vivir de una sociedad en determinado tiempo. De ahí que el saber transitado se vigoriza y sobrepasa el límite de la crítica, para explicarse el porqué y cómo de estos acontecimientos, pues la Historia no pretende resaltar personajes aislados de un proceso social, sino colectivos que, organizados o no, promueven cambios significativos y espontáneos en el acontecer político y social. Generalmente, la gran totalidad de historiadores no trazan objetivos comunes, y por esta razón hay nulidad en el debate y la crítica.

En este sentido, los datos históricos de la parroquia nos remiten hacia 1557 (fundación de Cuenca), donde los españoles debido a la presencia de manantiales hirvientes designan a este lugar como Baños (Albornoz 1951). Asimismo, la existencia de minas de oro y plata en el sector había despertado el interés de los colonizadores, llevándolos a fundar el "ayllu de minas" con el nombre de Minas del Espíritu Santo de Baños. Para 1776, por la Real Orden de Carlos III de España, esta localidad adquiere la categoría de pueblo (Chacón 1986), siendo denominado como Espíritu Santo de

\footnotetext{
* Universidad de Cuenca. Correo electrónico: miguel.novillo@ucuenca.edu.ec

** Centro Regional de Estudios Socioculturales, CERES. Correo electrónico: elsarosariosinchi@gmail.com
} 
Baños. Posteriormente, en 1784, por medio de la cédula Real de San Lorenzo, Baños se creó como curato del Obispado de Cuenca, adquiriendo así la categoría de parroquia eclesiástica.

La trayectoria histórica de larga data que acompaña a Baños soporta la conformación de imaginarios, memorias e historias de vida. Sin embargo, estos aspectos van en detrimento pues el inminente avance de lo urbano frente a lo rural absorbe las manifestaciones culturales y populares, que, paulatinamente, se van desestructurando y configurando para satisfacer las nuevas necesidades y exigencias sociales. Así, actividades artesanales -como es el caso de los encauchados- no están en capacidad de sobrellevar dichas exigencias y, por tanto, están en vías de desaparición. Fenómeno que tras de sí lleva redes o nexos con otras actividades, parte de la historia de Baños, referidos específicamente al contrabando de aguardiente.

El presente artículo pretende evidenciar una actividad artesanal que se desarrolló a mediados del siglo XX vinculada a la elaboración de encauchados (perras, zamarros, ponchos, bombas) y al contrabando de aguardiente, como parte de la memoria histórica y patrimonio cultural de Cuenca y el Ecuador. Además de reflexionar a partir de este caso de estudio términos como patrimonio, memoria e identidad.

Partimos de la concepción de patrimonio y cultura popular propuesta por Claudio Malo, quien indica que esta "se inclina a preservar las tradiciones propias de cada comunidad esencialmente en aquellos aspectos considerados como definidores e identificadores de grupo" (1996: 97). Identificación cultural que, a decir de Funari (2004), se desarrolla mediante la preservación de la memoria, que implica un proceso actual, emotivo y afectivo que surge desde un grupo social y se encuentra en una relación permanente entre el recuerdo y el olvido (Nora 2009).

La metodología utilizada en esta investigación se fundamentó en el registro de historias de vida a dos actores locales, uno de ellos vinculado a la elaboración de los encauchados y otro dedicado al contrabando de alcohol, relación directa que constituye un elemento identificador de la parroquia (hace años). Para el registro de los testimonios se realizaron cuatro entrevistas a cada actor, y cada una de estas implicó conversaciones extensas.

Las historias de vida como método centran su argumento en que el hombre no es un dato sino un proceso, el que actúa en forma creativa en su mundo cotidiano, como afirma Ferrarotti (2007), lo social implica historicidad. Otro de los argumentos que sustenta el uso de este método en este trabajo es la necesaria vinculación entre texto y contexto, es decir, implica la posibilidad de la autopercepción del individuo-sujeto de la historia de vida en su vinculación experiencial con el ambiente contextual. Finalmente, el aporte fundamental de las historias de vida a la investigación social es la capacidad de expresar y formular lo vivido cotidiano de las estructuras sociales, formales e informales. Es aquí en donde confluye la memoria del contrabando de aguardiente con los encauchados, hechos que como parte de la historia local, invitan, por un lado, a reflexionar acerca de la historiografía tradicional que recae en nociones esencialistas (Aravena 2014) $\mathrm{y}$, por otro lado, se presenta como insumo para la construcción de una memoria colectiva de clave patrimonial ${ }^{2}$.

Desde la Colonia hasta finales del siglo XX, la comercialización y la distribución de aguardiente fue monopolizada por la Corona durante la Colonia y por el Estado en la República. En el tiempo fueron varias las leyes y normativas que se trabajaron a favor de mantener el estanco del aguardiente con el fin de captar un importante rubro para la caja fiscal. Sin embargo, en la práctica no había ni ley ni reglamento, por más radical que se decía, capaz de frenar una actividad en crecimiento: el contrabando de aguardiente. Al contrario, lo incentivaba mucho más, porque se mostraba como una posibilidad económica favorable que era aprovechada por los contrabandistas, porque la ley no impedía la burla de los propios ejecutores, y porque existía una alta demanda de aguardiente en la ciudad de Cuenca (a nivel general en las provincias de Azuay y Cañar). (Chacón 1986). En este contexto, el trabajo del artesano del caucho tuvo gran importancia, porque fue el principal proveedor de los envases del alcohol de contrabando, llamadas "las perras".

Bajo esta mirada, es admisible introducir breves referencias respecto del contrabando y el alcohol en la sociedad ${ }^{3}$, pues generalmente el estudio de las bebidas alcohólicas ha sido tratado por materias como biología, medicina, salud pública y psicología social (Dietler 2006), que enfocan su análisis como un problema patológico (social e individual). Sin embargo, a partir de 1980, la antropología transforma esta perspectiva de análisis con el planteamiento de que el alcohol y su consumo representan un 
componente sociocultural, sustentando su argumento en estudios etnográficos (Valdez et .al. 2010) y también históricos, por ello, existe un progreso en el entendimiento del empleo de la bebida, pasando desde aspectos de salud pública hasta miramientos antropológicos.

Las dos perspectivas mencionadas generan otro tipo de relaciones, entre alcohol y artesanía, mano de obra, política, economía, etc., denotando un patrón casi universal efectuado en múltiples culturas (Lau 2012), hasta considerarse parte integral del estudio económico y político, dibujado como estrategia que permite establecer mecanismos de poder, control y autoridad (Dietler 2006). Por tanto, el alcohol no implica un uso específico en la sociedad, sino que vincula otras manifestaciones sociales, como veremos más adelante.

En términos generales, la situación de las tradiciones, la memoria y el patrimonio de Baños está construyéndose o en riesgo de desaparecer, teniendo en consideración que, entre las varias medidas tomadas por el gobierno para palear el saqueo, desaparición y destrucción del patrimonio, estuvo la denominada creación del Sistema Nacional de Bienes Culturales que resultaba del producto del Inventario Nacional de Patrimonio, como medida emergente y por decreto, para clasificar los bienes del país, con el apoyo de expertos en las múltiples materias y por medio de la conformación de equipos interdisciplinarios.

Los objetivos planteados por este decreto son, por un lado, no solo salvaguardar los bienes ya conocidos, sino, buscar nuevos objetos y elementos culturales, a partir de la revalorización de patrimonios descuidados por las políticas gubernamentales. En este sentido, sostenemos que el registro impulsado por el gobierno ecuatoriano ancló sus propósitos en la identificación de los bienes culturales nacionales, con miras a su conservación y divulgación. Además, dicho registro permitió la construcción posterior de nuevos referentes culturales en un contexto sociocultural en el que las narrativas nacionales y sus referentes deben negociar sus posibilidades significativas con elementos más lábiles y de consumo extendido provenientes de los contextos globales y la sociedad de masas (Cabrera 2011) (Figura 1).

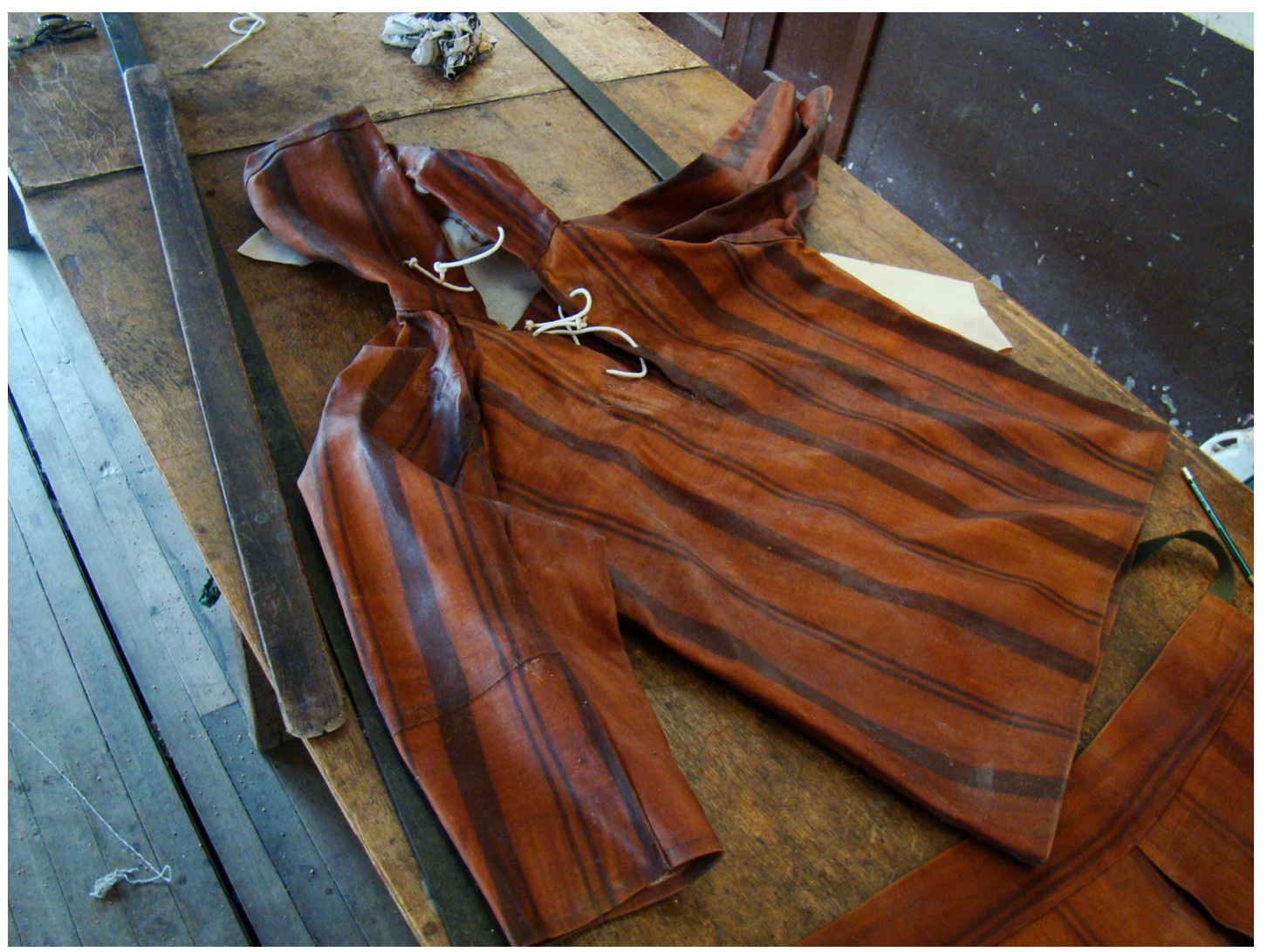

Figura 1. Poncho de caucho. Utilizado principalmente por los contrabandistas para cruzar el páramo. 


\section{Memoria y Patrimonio en riesgo: referentes conceptuales y reflexiones}

El concepto de Patrimonio ha estado en permanente configuración en el tiempo, sin embargo, según la Organización de las Naciones Unidas para la Educación, la Ciencia y la Tecnología (UNESCO) a partir de la institucionalización de las manifestaciones culturales, ha categorizado al Patrimonio Cultural como:

Las tradiciones o expresiones vivas heredadas de nuestros antepasados y transmitidas a nuestros descendientes, como tradiciones orales, artes del espectáculo, usos sociales, rituales, actos festivos, conocimientos y prácticas relativos a la naturaleza y el universo, y saberes y técnicas vinculados a la artesanía tradicional ${ }^{4}$.

En tanto que el Patrimonio Cultural, según la UNESCO, hace referencia a:

Las tradiciones o expresiones vivas heredadas de nuestros antepasados y transmitidas a nuestros descendientes, como tradiciones orales, artes del espectáculo, usos sociales, rituales, actos festivos, conocimientos y prácticas relativos a la naturaleza y el universo, y saberes y técnicas vinculados a la artesanía tradicional ${ }^{5}$.

Mientras que el Patrimonio Cultural Inmaterial incluye además de las tradiciones heredadas del pasado, sus usos rurales y urbanos contemporáneos característicos de diversos grupos culturales ${ }^{6}$. Al respecto, la Ley Orgánica de Cultura del Ecuador, expedida en el 2016, en su Art. 52, señala que lo intangible o inmaterial hace referencia a:

[...] todos los valores, conocimientos, saberes, tecnologías, formas de hacer, pensar y percibir el mundo, y en general las manifestaciones que identifican culturalmente a las personas, comunas, comunidades, pueblos y nacionalidades que conforman el Estado intercultural, plurinacional y multiétnico ecuatoriano ${ }^{7}$.

Este concepto agrupa entonces diversos elementos que son inherentes al hombre, tanto en sociedades no tradicionales y tradicionales, aunque es en estas últimas donde podemos encontrar varias manifestaciones culturales vivas, asociadas a su cotidianidad. Sin embargo, en la mayoría de los casos, en nuestro ámbito, estos conocimientos están en peligro de desaparecer.

La capacidad de trasmisión de lo inmaterial, los espacios donde se desarrollan algunas de estas manifestaciones, los saberes tradicionales acerca de técnicas, la tradición oral, se ven afectados por el avance incontrolado de programas económicos, políticos y sociales que no tienen una visión conciliadora y de reconocimiento de la diversidad. En el caso ecuatoriano, los términos Patrimonio, la memoria y la identidad han sido objeto de manipulación para servir a intereses de sectores políticos o económicos de poder, donde las nociones fundamentales de la Historia y Patrimonio son mínimas, en ocasiones, inclusive, desconocidas. Asimismo, especialistas, tecnócratas y burócratas culturales son reconocidos como dueños y administradores del patrimonio (Cabrera 2011) situación que aleja al Patrimonio de sus verdaderos detentores. Como consecuencia del mal uso de los términos, las Ciencias Sociales dentro del sistema educativo ecuatoriano ha asumido un proceso de desarrollo conceptual muy limitado y mal enfocado en lo que concierne a las necesidades emergentes que tiene el país respecto de temas identitarios, étnicos, culturales, entre otros.

Ahora bien, las leyes y las normativas patrimoniales ofrecen concepciones de partida para el quehacer institucional -con aciertos y desaciertosfrente a las expresiones culturales de los pueblos. Sin embargo, es necesario reconocer la amplitud y complejidad de las definiciones de patrimonio, memoria e identidad, y la importancia de que su análisis sea integral. Incluir a uno dentro del otro permite entender las implicaciones históricas, sociales y culturales de una o más prácticas sociales en el tiempo y en un espacio determinado, como es el caso del objeto de estudio de este artículo.

El concepto de Memoria es, en sí mismo, bastante ambiguo, puede abordarse desde distintos lugares y tiene que ver con el momento histórico desde donde se lo estudie. Lo mismo sucede cuando se intenta definir la identidad, sobre todo en la dicotomía colectiva/individual. El tercer concepto aquí planteado tampoco escapa a esta ambigüedad, ya que puede afirmarse que el concepto de Patrimonio y lo que este incluye o excluye, así como la forma de abordarlo, fue cambiando a lo largo de los años, 
de las épocas y de los marcos teóricos vigentes para cada ciencia que lo estudia.

De esta manera, el primer concepto que viene a la reflexión es el de memoria histórica. Para Walter Benjamin (2005), la memoria es el medio con el que se pueden desenterrar los secretos lejanos del pasado, de la tradición, rescatarlos de la oscuridad y revelarlos en el presente. El pasado, trabajado desde la memoria, aparece como una topografía del recuerdo, esto implica una nueva posición para el hombre, aquella que la sitúa entre un pasado y un presente. Esos fragmentos del pasado, aproximados mediante la actividad "arqueológica" o destructiva, sugieren un nuevo modo de pensar en la historia.

Las relaciones entre historia y memoria se abordan aquí desde la perspectiva de la historia del tiempo presente, en la que la memoria emerge como objeto de estudio. Desde las posibilidades que este concepto ofrece y la pluralidad de sus clasificaciones, nos centramos en la memoria colectiva.

Además, se considera que es posible trabajar con las identidades comprendiéndolas de forma no esencialista. Es decir, como proyectadas a partir de discursos específicos y con finalidades diferentes. La identidad, en este contexto, se comprende como subjetiva, fluida y múltiple (Escosteguy 2001: 150). Frente a la fluidez y las subjetividades, la valorización de la diversidad se convierte en una alternativa para la construcción de patrimonios plurales.

La suerte de imaginario, con construcciones subjetivas y simbólicas, que las personas hacen de su medio como resultado de la representación e interpretación de su relación con él, no es producto de una creación individual, sino como tal, es una percepción colectiva. Este imaginario representa un complejo conjunto de componentes inherentes a las acciones del ser humano y su entorno natural, social y cultural. Como lo expone Cornelius Castoriadis, los imaginarios designan las representaciones sociales encarnadas en instituciones, es decir, mentalidad, cosmovisión, conciencia colectiva o ideología (Figura 2).

Por su parte, el Patrimonio es considerado como la "síntesis simbólica de los valores identitarios de una sociedad que los reconoce como propios". El concepto aplica a las sociedades consideradas

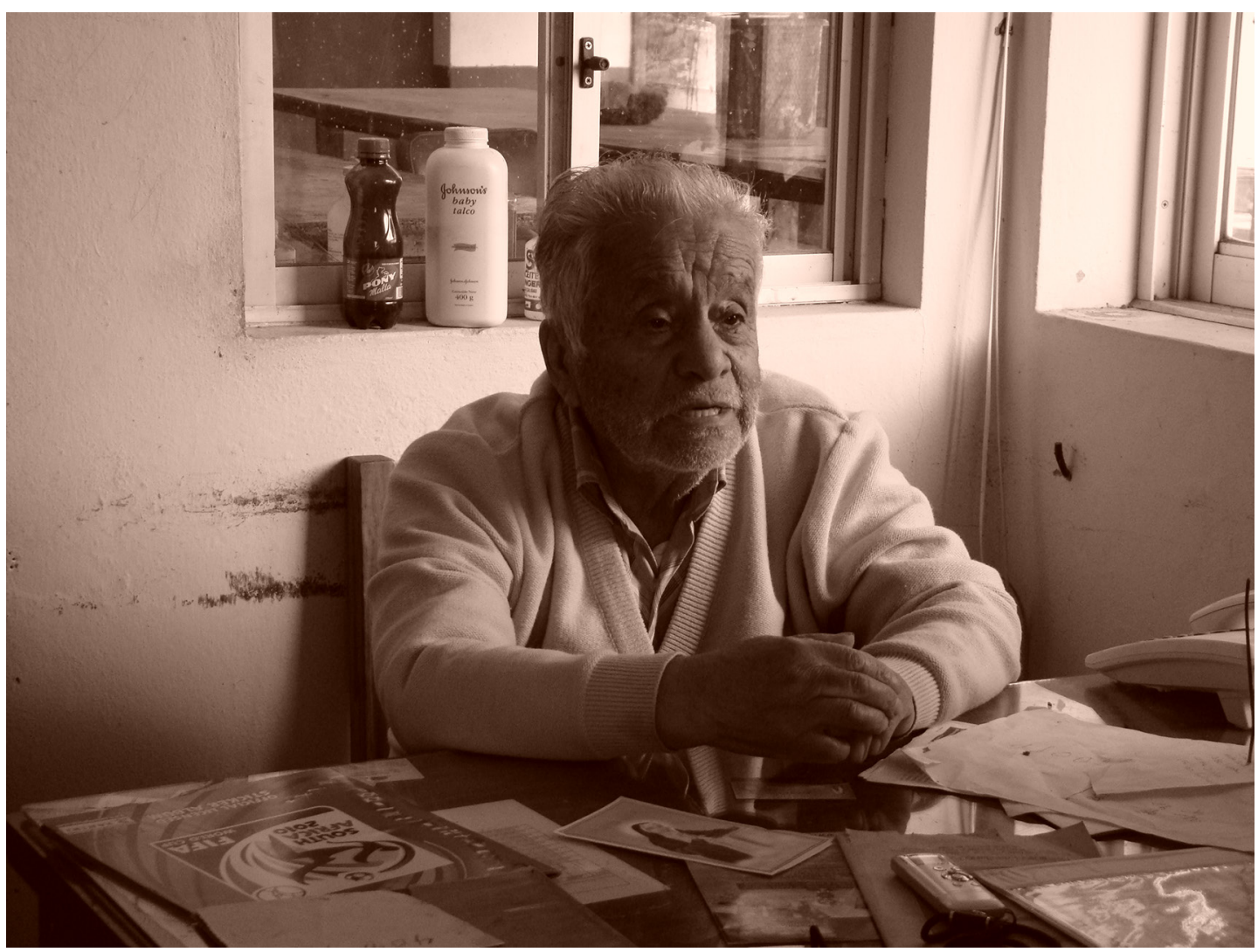

Figura 2. Don Eloy Cedillo. Último artesano dedicado a la elaboración de encauchados. Portador de memoria e identidad de Baños. 
tradicionales. Sin embargo, en sociedades no tradicionales las prácticas, tradiciones y costumbres pueden ser olvidadas y a su vez generar un vacío o sesgo en sus bases (Santana 1998), aspecto que -en varias ocasiones- es aprovechado para implantar un argumento patrimonial y su respectivo llamamiento a la memoria colectiva, sostenido en beneficios de infraestructura y económicos, o en el enajenamiento del patrimonio de los moradores habituales del territorio en que se enmarca lo que implica altos costes de mantenimiento.

También, el patrimonio es entendido como el acontecimiento o materialidad que nos "remite a las relaciones que los pueblos y sus élites tienen con su pasado; los discursos que los Estados y sus gobiernos construyen sobre la memoria, la identidad y la historia local o nacional" (s.a. 2009: 7).

Así, el Patrimonio Cultural se ha ido consolidando a partir de la conformación de "corpus culturales", sean materiales e inmateriales, sin percatarse del tratamiento, manejo y funcionalidad que le dan al mismo. Para su registro, se llenan grandes fichas con información antropológica, arqueológica, arquitectónica, etnológica, no obstante, la realidad en que viven los protagonistas y verdaderos dueños del patrimonio se ve pauperizada, pues, las políticas rescatan la materialidad mas no a los actores que son constitutivos o incluso vivificadores de la cultura patrimonial.

Como resultado de esta comprensión de patrimonio, la nación se encuentra enriquecida de objetos y sujetos patrimoniales, que en nada perturban las bases de poder (económico y político), y no tienen razón de ser en un medio con necesidades consideradas de vital importancia, como el empleo, alimentación, educación y salud. Al final, todos pretenden, quieren, anhelan, luchan a perpetuidad por ser patrimonio, sin sentir o valorar lo que eso implica. Desde esta perspectiva, como lo anticipan José Prada y Sandra Pesantez (2017), la cultura ha dejado de ser un fin en sí misma y ha pasado a significar la promoción económica local asociado al turismo.

Posiblemente la transfiguración de los cánones culturales en pro del patrimonio, lo único que están logrando es la aniquilación de la imaginación social para presentar y representar los elementos característicos de cada persona, ciudad, comunidad, región, y que son elementos propios y verdaderos de su "patrimonialidad" no institucionalizada.

Es innegable que la construcción de ideas, pensamientos e imaginarios que el patrimonio cultural mantiene con las memorias públicas, es tan íntima y recíproca a la vez que, a falta o falencia de conceptualizaciones, todo un complejo sistema de entendimiento cultural surge para catalogar a tal o cual bien como patrimonio cultural.

Es por esta razón que los "enfoques" o "parámetros" con los que se pretenden considerar a los nuevos elementos como patrimonio deben, necesariamente, ser redefinidos, pues deben pensar en el simbolismo y funcionalidad que los elementos cumplan en la sociedad, tomando en consideración el aspecto geográfico, histórico, humano y de consumo en la que se desenvuelven las acciones de las personas, proveyendo de diversos usos y sentidos a un espacio.

Tanto el registro institucionalizado-oficializado por el criterio del erudito como el señalamiento de que toda manifestación cultural debe ser considerada como patrimonial conlleva problemas, que bien los advierte Santiago Cabrera (2011: 112). El primero lleva a un estado de "petrificación" de la cultura, mientras que el segundo acarrea un estado de banalización de las manifestaciones culturales, por eso es indispensable analizar desde el punto de vista de la producción y reproducción de dichos elementos para ser considerados como patrimoniales.

Por lo expuesto, es necesario que hoy lo patrimonial no se encuentre relegado solo a los expertos, sino que también sea la comunidad la que tenga la facultad de "hacer patrimonio", como lo propone Dromaels (2012: 12). Al ser el patrimonio "soporte transmisible de la historia y la identidad en la experiencia colectiva", solo un proceso simbólico de patrimonializacación -una legitimización social-, en donde una comunidad reconoce y valoriza un objeto (material o inmaterial) que representa su historia e identidad en un momento determinado, es capaz de reconstruir su memoria colectiva. Así lo patrimonial expande su escala temporal; ya no solo tiene valor en el pasado, sino también en el presente.

En este proceso, las fuentes orales de la memoria local se convierten en recursos necesarios e importantes para experimentar y construir una versión más plural y quizá más polifónica de su pasado y su presente. Los narradores particulares se inscriben en un ámbito colectivo, desde allí nutren su memoria y construyen su discurso en donde rememoran los núcleos de experiencia que sustentan sus identidades y sus pertenencias sociales, así como lo indica el Art. 28 de la Ley Orgánica de Cultura del Ecuador vigente: 
[La memoria] es la construcción colectiva de la identidad mediante la resignificación de hechos y vivencias socialmente compartidos por personas, comunidades, pueblos y nacionalidades, que desde el presente identifican y reconocen acontecimientos, sucesos y momentos de trascendencia histórica, arqueológica, antropológica o social.

Los narradores son, por tanto, conductos hacia los temas y motivos de las memorias diversas en un pueblo (Portelli 1989). La misma ley en mención ratifica que:

"las personas, comunidades, comunas, pueblos y nacionalidades, colectivos y organizaciones culturales tienen derecho a construir y difundir su memoria social, así como acceder a los contenidos que sobre ella estén depositados en las entidades públicas o privadas"8.

Hasta aquí se exponen los soportes teóricos y conceptuales que guían la investigación. Las distinciones y reflexiones formuladas y retomadas revisten especial importancia y vigencia para el propósito del trabajo. Solo el análisis adecuado permitirá dar una categorización acertada de patrimonio -sea material o inmaterial-, pues lo trascendental es el aspecto social y humano que lo dota de sentido (Cabrera 2011).

\section{Los encauchados y el contrabando de aguardiente: descripción}

En gran parte de las parroquias rurales del cantón Cuenca aún subsiste una suerte de artesanía tradicional, desarrollada con técnicas poco sofisticadas, con herramientas relativamente simples y trabajadas originalmente en un contexto familiar. Actualmente estas actividades enfrentan ciertos cambios que responden a la dinámica cultural en la que estamos inmersos. Herald Einzman y Juan Martínez, al respecto, manifiestan que estas artesanías son "para uso doméstico o solamente para un mercado muy limitado y local, están a punto de ser sustituidas por técnicas industriales y productos modernos y sintéticos, que no siempre son baratos ni prácticos, pero que se prefieren debido a un cambio de estimación general" (Einzmann y Martínez 1993: 56).
Pese a los cambios evidentes, los sólidos componentes culturales que caracterizan a la parroquia Baños la hacen dueña de una notable identidad expresada en sus diversas manifestaciones que, aun sin representar un gran ingreso económico, son componentes esenciales de sus habitantes. Es en este contexto que a partir de la memoria histórica se registra y describe la actividad artesanal conocida como "los encauchados". Productos derivados del quehacer tradicional (con más de medio siglo de vigencia).

Entre sus actores iniciales se destacaron Luis Jiménez, Eloy Sigüenza, Héctor Cedillo (hoy difuntos). En la actualidad sobresale Eloy Cedillo, quien aprendió el oficio de su padre (Héctor Cedillo). Hoy, con 89 años de edad, él continúa con la producción de los encauchados en la parroquia, siendo el heredero de historias, vivencias y memoria en torno a esta labor (Figura 3).

En la actualidad la producción artesanal de los encauchados atraviesa una notable disminución, debido a la difusión y gran aceptación de nuevos productos (precios bajos y asequibles) que tienen

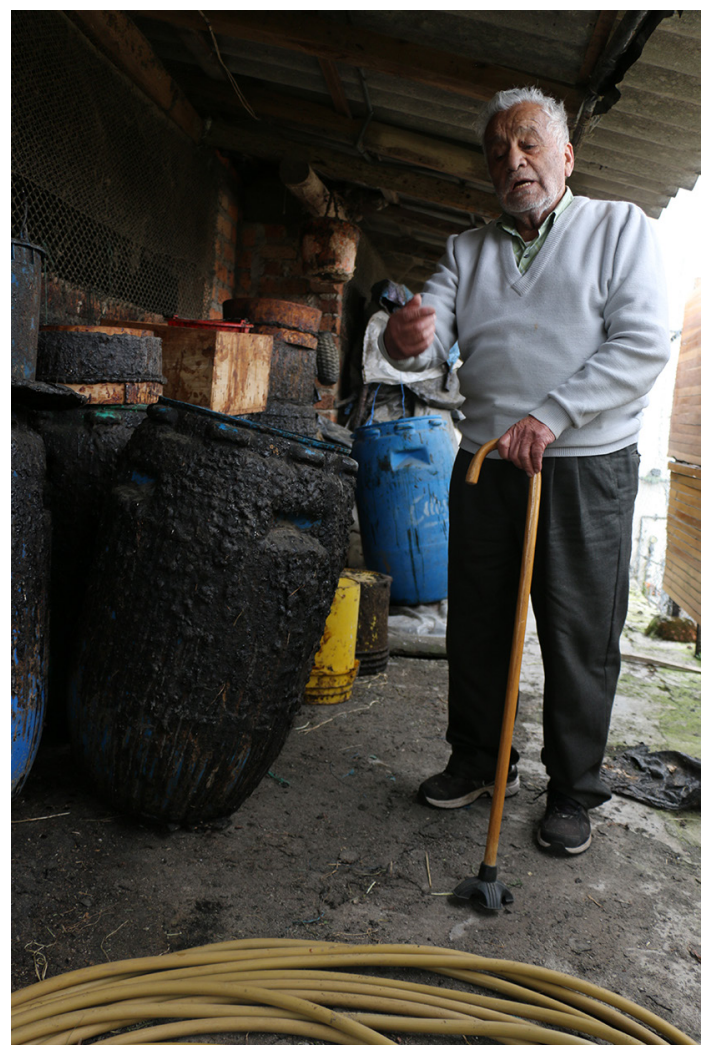

Figura 3. Taller artesanal de encauchados. Don Eloy Cedillo, propietario. 
como materias primas el nylon y el sintético. Sin embargo, la narrativa de Eloy Cedillo nos da cuenta que, a pesar que esta actividad no le genera un rédito económico sustentable, su identidad está anclada a su artesanía, y que esta a su vez constituye parte de su historia individual y colectiva como bañense.

Eloy lleva más de 70 años en este sector artesanal. Si bien desde niño colaboraba con su padre en la elaboración de los encauchados, su primera experiencia directa con esta producción fue a partir de un ejercicio escolar; él recuerda que le solicitaron una manualidad, y al tener la disponibilidad del material (cuacho) en casa y los conocimientos de su padre, no solo cumplió con la actividad escolar, sino que hizo de esta labor su trabajo de vida.

El emprendimiento realizado lo convirtió en el pionero en el Austro, sobre todo en la elaboración de las bombas para el carnaval, una fiesta de gran importancia para la ciudad. Las bombas tuvieron una gran acogida en la ciudad, sin embargo, al ser elaboradas a base de caucho, resultaban muy duras para el juego del carnaval, ya que este consistía en lanzar bombas de agua a la gente. Por esta razón, a los pocos años, se impidió la elaboración de bombas de caucho. Aun así, el desarrollo de esta primera artesanía significó el surgimiento de un gran artesano.

Lo mío es hereditario, mi papacito hacía pero rústico, entonces después fui mejorando yo. Ya en la escuela ya hice yo. Los globitos para carnaval, eran duras. Yo hice un trabajo manual que me mando mi profesor Braulio Durán, entonces un día de esos como vacaciones nos dice: hagan un trabajo manual de lo que quieran y lo que puedan. Entonces yo hice el primer globo, ponía el caucho y le puse un poquito de azul de metileno que antes nosotros usábamos mucho para escribir en las pizarras de piedra, entonces me salió, de arte que sé, me salió un globito o sea una bombita. Entonces yo le llevo al profesor, el profesor se sorprende, entonces él enseguida ve unas gentes y hacemos una sociedad. Él renunció a la escuela y se puso a trabajar conmigo, hacíamos zamarros, perras, ponchos ${ }^{9}$ (Figura 4).

Para la elaboración de los productos a base de caucho, los artesanos utilizaban la materia prima proveniente de la provincia de Esmeraldas. Entre

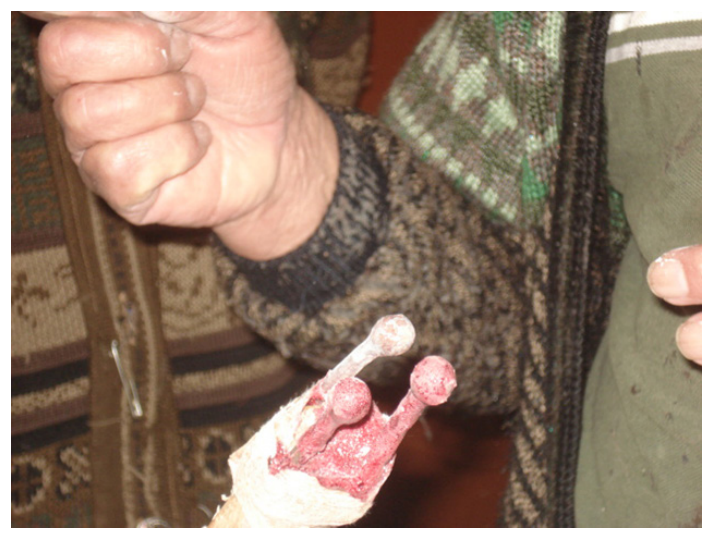

Figura 4. Molde de bombas de caucho. Elaboradas para la fiesta de carnaval, este invento se propagó por la ciudad a partir de un deber escolar.

los años 60 y 70 la comercialización de los encauchados fue de gran importancia para la economía de la parroquia. La magnitud y la "bonanza" de los encauchados fue tal, que don Eloy en sus momentos de auge productivo llegó a contar con 50 obreros en su taller.

La producción era diversa: globos de carnaval, carpas, zamarros, ponchos de agua y "perras" de aguardiente, gran parte de estos productos estaban destinados para el consumo local y regional, en especial para la gente que trabajaba en los campos, para viajeros y contrabandistas de alcohol. También su producción tuvo un alcance internacional -debido a la acción comercial de intermediarios ${ }^{10}$ - en países como Colombia y Perú, esta vinculación externa se dio, principalmente, con las bombas de carnaval.

De miles mandábamos al Perú y Colombia, pero no yo sino Juan Eljuri, Pedro Bohórquez, porque ellos nos compraban todo nuestro trabajo. Después hicimos las carpas, pero eso también ya dejé porque salió el material de nylon, chinas que hacen en el Milchichig. Ahora hago zamarritos, ponchitos, pero ya poco, estos llevan los que necesitan para sacar la leche, para andar en la shulla. Muchos de mis amigos me piden que ya deje, pero todavía puedo hacer, ¿porque no voy hacer? ${ }^{11}$

Un acontecimiento vinculado directamente con los encauchados fue el contrabando de aguardiente desde los yungas o "calientes" de la serranía y la costa ecuatoriana, donde se procesaba el alcohol basado en caña de azúcar. Desde la literatura 
ficcional (realismo social) se mencionan a Patul, Naranjapata y Sanaguín como rutas que seguían los contrabandistas para abastecer de licor a varias de las cantinas de la ciudad de Cuenca y fuera de ella.

La producción de aguardiente fue una actividad que marcó a las provincias del Azuay y Cañar. Hasta 1925 estas dos provincias alcanzaban una producción de alcohol de más del $60 \%$ a nivel nacional, esto implicó la aplicación de regulaciones y fuertes presiones legales por parte del Estado respecto de la producción; situación que condicionó a los productores de alcohol a una elaboración regulada por un límite de producción: una hectárea de caña de azúcar podía producir 3 mil litros ${ }^{12}$.

En esta coyuntura, nuevos actores asociados a la elaboración y expendio del aguardiente, emergieron: los contrabandistas y los guardaestancos. Los primeros con el objetivo de burlar la nueva reglamentación impuesta y los segundos con la finalidad de asegurar la llegada de los tanques sellados de alcohol al estanco regional. Sin embargo, estas acciones estaban lejos de poder ser llevadas a cabo, pues los guardaestancos eran "víctimas" de los sobornos de los contrabandistas a cambio del libre tránsito y abastecimiento del alcohol, principalmente en las cantinas.

El escritor G. H. Mata, en su novela Sanaguín, focaliza algunas de las características de esta etapa.

Por un lado, están los contrabandistas que quieren ganar plata de la venta del alcohol: "Le niegan a uno el derecho de moler, y los sanaguinejos pues tienen que contrabandiar, vaya! El hombre busca su pan con sudor de su frente, señor. Pobre Riera, él era el cabecilla de los contrabandistas". Mientras que, en el otro extremo están los guardas; encargados de vigilar a los contrabandistas. Ellos realizaban grandes emboscadas a los contrabandistas que, en sus mulas llevaban el licor, para posteriormente quitárselo, bebérselo, y muchas de las veces, incluso, terminaban en enfrentamientos y muerte: "Desafió mismo a los guardas, saliendo con las mulas que ellos habían visto antes de querer entrar a la casa del Oscar. Entonces los guardas aprovecharon ese descuido (...) un tiro en el pecho le habían metido" (Mata 1942: 120).

Se conoce que la sociedad cuencana gustaba de las fiestas y del jolgorio, las que tenían días de duración. Donde se preparaban grandes cantidades de platos, como cuy, puerco y gallinas, además de contar con mucho más alcohol, que se obtenía fácilmente, dependiendo la fiesta y del dinero que se disponía: "Tengo entendido que en este Carnaval se consumieron aquí cinco mil litros de alcohol en los tres días" (Mata 1942: 13).

También existían labores artesanales, como la de los peluqueros que -muchas de las veces cumplían el papel de odontólogos, debido a que la ciudad no contaba con uno de estos profesionales-hacían uso del alcohol de contrabando:

El Oso antes de proceder a la extracción, lo primero que hacía era dar al paciente una copa de aguardiente para calmar los nervios y enseguida dos de sus opulentos operarios cogían al desgraciado hasta inmovilizarlo, entonces el "odontólogo" mediante una tenaza procedía a la operación. Un furibundo grito de la víctima que se oía a más de una cuadra, era la señal evidente de que la muela estaba fuera de órbita, gritos que el vecindario ya estaba acostumbrado a oír todos los días. Como era de esperar, los pacientes que, por lo regular sufrían desmayos, el amigo peluquero que tenía a la mano un frasco de agua florida, inmediatamente le hacía aspirar hasta que vuelva en sí (Abad 1981: 71).

Víctor Calderón, habitante de la parroquia Baños, fue un contrabandista de alcohol. Reconoce que el contrabando era una actividad que implicaba un alto riesgo, tanto para su vida como para su libertad. A pesar de ello, advierte que la precaria economía de su tiempo y los conocimientos que su padre (difunto) tuvo acerca de esta actividad, fueron factores decisivos en su temprana vinculación con este negocio. Sus recuerdos con el contrabando del alcohol nos conducen, por un lado, a los yungas o "calientes" de la serranía y la costa ecuatoriana y, por otro, a Luis Jiménez (difunto) y a Eloy Cedillo, principales productores de los encauchados, asentados en la parroquia (Figura 5).

Es, entonces, en estas memorias escritas y orales en donde se entrecruzan el contrabando de aguardiente y los encauchados. Gran parte de los contrabandistas de la parroquia y demás localidades de la provincia hacían uso de los encauchados de Luis Jiménez, Eloy Siguenza, Héctor Cedillo (todos fallecidos) y Eloy Cedillo. Entre los productos se 


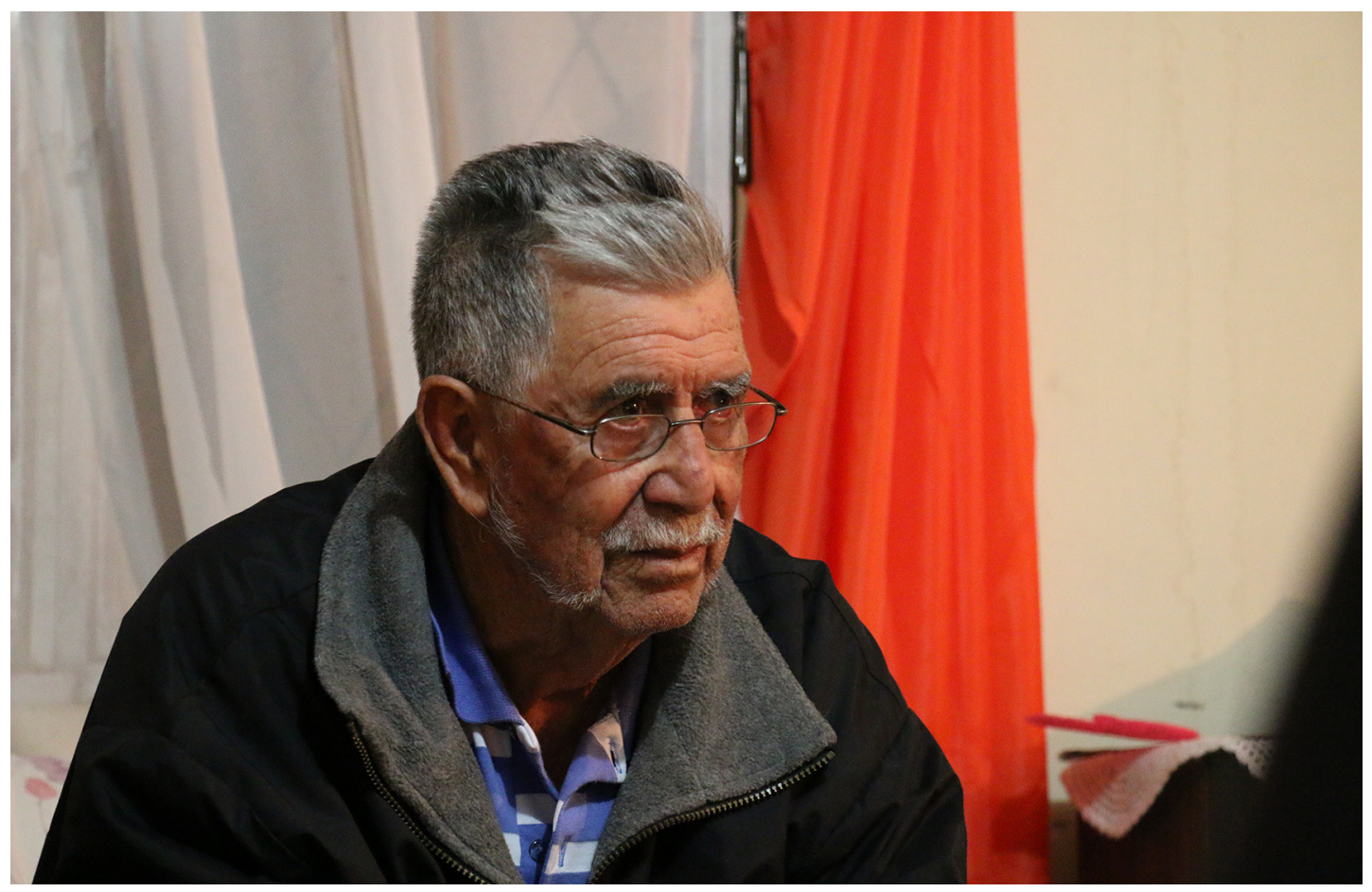

Figura 5. Don Víctor Calderón. Excontrabandista de aguardiente.

destacan a las "perras" (principal artefacto para transportar el alcohol), los ponchos y los zamarros.

De acuerdo con lo expuesto por don Víctor, eran varias las rutas las que seguían los contrabandistas para evadir a los guardaestancos, si bien tenían rutas fijas, ante la alerta de la presencia de los guardas en alguna parte de su recorrido común, optaban por tomar derroteros opcionales, siguiendo los cerros. El aguardiente era envasado en las "perras" de caucho y transportado sobre el lomo de una mula (Figura 6).

Antes de ser llenadas las "perras" de alcohol, debían pasar por un proceso de "desintoxicación" del caucho, es decir, debían someterse a una fase de remojo de dos o más días para disminuir el hedor del caucho. La "perra" más grande tenía la capacidad de trasladar hasta 40 litros de aguardiente. Al ser el caucho un material resistente, les permitía a los contrabandistas, por un lado, realizar un transporte seguro del alcohol, sin tener cuidado del posible derramamiento del producto y, por otro, ante la notificación de guardas en la ruta, les permitía lanzar las "perras" entre los pajonales para evitar el decomiso del producto.

El aguardiente provenía de algunas de las fincas ubicadas en la parroquia Chaucha, pero principalmente de la Hacienda de Juan Chica Balarezo, ubicada en la localidad de Iguiñán. Las rutas más conocidas atravesaban Chaucha y Pijilí, o Soldados y Chanchán. En estas rutas era frecuente encontrarse con los guardias de estancos, estos encuentros provocaban dos situaciones: el aguardiente y las mulas eran confiscados, o se propiciaban enfrentamientos entre guardas y contrabandistas.

Las mulas y las "perras" de aguardiente que eran retenidas por los guardias de estanco entraban en una suerte de "dinámica comercial", pues dichos guardias vendían a Eloy Cedillo (artesano de encauchados) los implementos confiscados que, a su vez, eran revendidos a los contrabandistas a quienes les retuvieron sus animales y el aguardiente de contrabando. Es decir, cuando existía confiscación, los contrabandistas acudían al taller de Eloy Cedillo a comprar sus propias pertenencias.

Otras rutas alternas usadas por los contrabandistas para burlar a los guardas eran Allpachaca, Yanasacha, Huasiloma:

...y después cuando venían los guardias a molestarnos, veníamos de un punto que se llama Alpachaca, veníamos noche para 


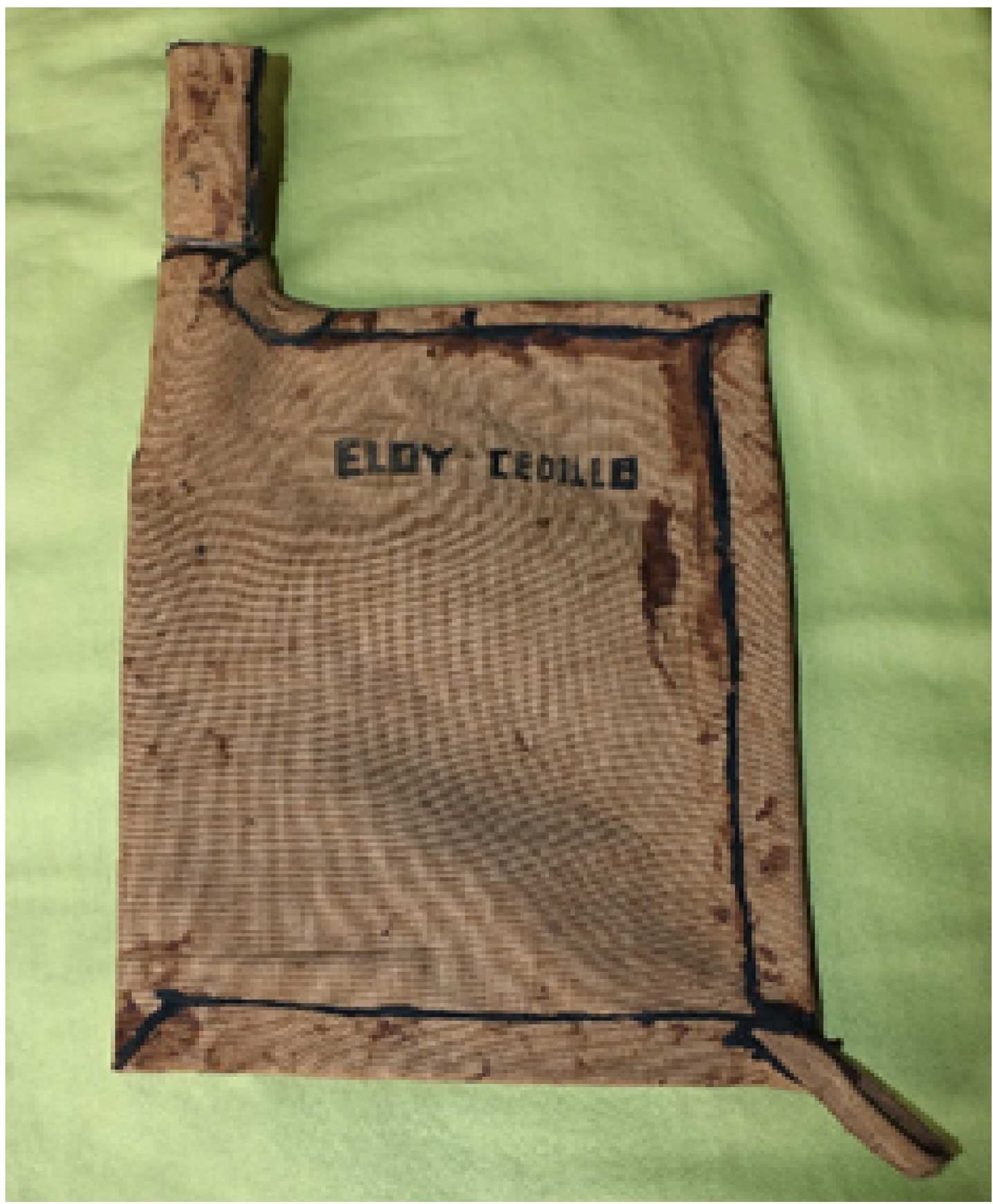

Figura 6. "Perra" de caucho. Servía para transportar aguardiente.

llegar a Baños en la mañana...caminando toda la noche, con una linterna que estaba por acabarse, algunas veces veníamos a oscuras. Veníamos a veces por Huasiloma, por el lado de Yanasacha, por ahí veníamos, así era nuestra vida ${ }^{13}$.
Además de las "perras", otros artículos encauchados como los ponchos y los zamarros fueron también de gran utilidad para los contrabandistas. La lona, material con el que están elaborados internamente los encauchados, les permitía a los contrabandistas soportar los inclementes fríos nocturnos propios 
de sus travesías. Entre 15 a 20 días era el tiempo que le tomaba a un contrabandista llegar con el aguardiente a la ciudad.

Finalmente, en la memoria del contrabando de Víctor Calderón está presente la muerte de su hermano, quien sufrió un paro cardíaco y murió en un lugar inhóspito propio de la travesía. Los contrabandistas tuvieron que llevar el cuerpo de su hermano al poblado más cercano para darle sepultura. Años más tarde, él y su familia regresaron para exhumar el cuerpo y trasladarlo hacia su lugar de origen: Baños. Un hecho da cuenta de los riesgos que implicaba su desarrollo.

\section{Reflexiones finales}

Es rápido y continuo el cambio que están atravesando las artesanías, la cultura popular, memoria e identidad, principalmente en las zonas rurales. Sin embargo, se debe reconocer la diversidad y fortaleza de algunas prácticas culturales que propician una identidad y memoria en la población, en una suerte de lucha por la sobrevivencia, frente a las manifestaciones propias de la globalización.

En este contexto, se registra y valora la actividad realizada por Eloy Cedillo, quien ha demostrado resistencia frente a las modificaciones de consumo de hoy. A sus 89 años de edad sigue trabajando con el caucho y elaborando ciertos productos (previo pedido), como zamarros y ponchos de agua, por ejemplo. Aun así, don Eloy es consciente que a futuro esta actividad artesanal desaparecerá por completo, más aún, si se considera que ninguno de sus 10 hijos ha optado por dar continuidad a esta tradición.

Pese a la riqueza de expresiones culturales dentro de la parroquia, aquellas son muy frágiles ante la arremetida de la globalización; por ello la importancia de establecer conexiones constantes y competentes entre el patrimonio, la memoria y la identidad dentro de la parroquia y sus habitantes.

Como se ha podido revisar a lo largo de la descripción realizada, en torno a la producción del caucho se visibilizan otros elementos que también forman parte de la memoria y de la identidad de esta parroquia. Es el caso del contrabando de alcohol, actividad que no solo puede ser entendida desde el conflicto y la ilegalidad, al contrario, se convierte en una puerta de acceso para abordar el contexto festivo local y regional, asociado al consumo de bebidas alcohólicas que, como señala Michael Dietler (2006: 232), son parte o constituyen una parte especial de la cultura material, que sin embargo no se conserva pues es asimilado por el organismo humano pero que genera una simbolización de conceptos de identidad.

Si bien el presente texto registra y analiza una actividad artesanal (encauchados) y su relación con el contrabando de aguardiente, es importante destacar que el alcance de esta actividad fue mayor, pues los encauchados y sus derivados fueron también empleados en actividades agrícolas, viajes, fiestas, entre otras.

Finalmente, parecería que las artesanías están destinadas a desaparecer al estar en desventaja con la industria, pero lo real es que perviven en el tiempo, no como una forma neta de ingresos económicos, sino como una alternativa de subsistencia y como parte de la identidad. Las artesanías son elaboradas por el ser humano con predominio de sus manos y portan valores culturales de los entornos en los que se trabajan, de ahí la importancia que tienen como configuradoras de identidad de los pueblos, así como lo argumenta Claudio Malo:

Consciente o inconscientemente se cree que el cambio puede acabar con aquellos contenidos que proporcionan la satisfacción de sentirse partes de un grupo menor que les brinda seguridad y sentido de pertenencia. Los niveles de comunicación son más profundos en colectividades de este tipo en las que se comparten áreas más amplias de la vida. Los símbolos, mecanismo de comunicación, ideas y visiones de la realidad están en este caso legitimados por la reiterada repetición a lo largo de los años. Cuando se pregunta a una persona por qué piensa o actúa de tal manera, una respuesta muy frecuente suele ser: "porque así lo hacían nuestros mayores" (Malo 1996: 97).

\section{Agradecimientos}

Se agradece al Centro de Escritura Académica Killkana de la Universidad de Cuenca, al Centro Regional de Estudios Socioculturales (CERES), a don Eloy Cedillo y a don Mario Calderón por compartir con nosotros sus historias de vida, y a los evaluadores de este artículo. 


\section{Referencias Citadas}

Abad, O.

1981 Cuenca y Yo. Editorial Amazonas S. A. Cuenca.

Albornoz, V.

1951 Acotaciones a las relaciones geográficas de las Indias concernientes a la gobernación de Cuenca. Ediciones Talleres Tipográficos del Consejo Cantonal de Cuenca, Cuenca.

Antón, J.

2004 El antiguo trapiche de mascarilla, la memoria de la esclavitud y el patrimonio material afroecuatoriano.

Aravena, $\mathrm{P}$.

2014 "Patrimonio, historiografía y memoria social: "presentismo radical' y abdicación de la operación histórica". Revista Diálogo Andino. No 45, 2014, pp. 77-84.

Barlett, P.

1980 "Reciprocity and the San Juan Fiesta". Journal of Anthropological Research, Vol. 36:116-130.

Benjamin, W.

2005 Libro de los pasajes. Ediciones Akal, Madrid, España.

Cabrera, S. (compil.)

2011 "Religiosidad popular en el Santuario de El Quinche". En Cabrera Hanna, Santiago. Patrimonio cultural: memoria local y ciudadanía, pp. 121-143, Corporación Editora Nacional, Ecuador.

Cabrera, S. (compil.)

2011 "Introducción". En Cabrera Hanna, Santiago. Patrimonio cultural: memoria local y ciudadanía, pp. 7-16, Corporación Editora Nacional, Ecuador.

Castillo, C; Sanhueza, M. y Corcuera E.

2012 "Identidad y memoria histórica del tejueleo artesanal: un oficio maderero en riesgo de extinción en la región de Aysén”. Conserva, $\mathrm{N}^{\circ} 17$, pp. 53-67.

Chacón, J.

1986 Historia de la Minería en Cuenca. Universidad de Cuenca Instituto de Investigaciones Sociales, Cuenca.

Dietler, $\mathrm{M}$.

2006 "Alcohol: Anthropological/Archaeological Perspectives". Annual Review of Anthropology, Vol. 35: 229-249.

Dormaels, $\mathrm{M}$.

2012 "Identidad, comunidades y patrimonio local: una nueva legitimidad social”, en Alteridades, 22 (43), pp. 9-19.

Einzmann, H y Martínez, J.

1993 La Cultura Popular en el Ecuador, CIDAP, Cuenca.

Escosteguy, A.

2001 Cartografias dos estudos culturais. Uma versão latino americana. Belo Horizonte: Auténtica.

Ferrarotti, F.

2007 "Las historias de vida como método". Convergencia, Toluca, v. 14, n. 44, p. 15-40.
Funari, P.

2004 “Arqueología São Paulo, Editora Contexto". Revista Diálogo Andino. No 58, 2019, pp. 7-22.

Joffe, A.

1998 "Alcohol and social complexity in ancient Western Asia”. Current Anthropology, Vol. 39: 297-322.

Lau, G.

2002 "Feasting and Ancestor Veneration at Chinchawas, North Highlands of Ancash, Perú”. Latin American Antiquity, Vol. 13: 279-304.

LEY del Estanco

1916 Ministerio de Hacienda, Quito.

Ley Orgánica de Cultura

2016 Registro Oficial, Órgano de Gobierno del Ecuador, Quito.

Malo, C.

1996 Arte y Cultura Popular, CIDAP, Cuenca.

Mata, $\mathrm{H}$

1942 Sanagüín. Cuenca: Editorial Austral.

Mata, $\mathrm{H}$.

1968 Chorro Cañamazo. Editora Quito, Quito.

Mata, $\mathrm{H}$.

1982 Rumbo al Infinito. Editorial Biblioteca Cenit, Cuenca.

Nicholson, E.

1960 "Chicha Maize Types and Chicha Manufacture in Peru". Economic Botany, Vol. 14: 290-299.

Nora, $\mathrm{P}$.

2009 Les lieux de mémoire. Santiago: LOM.

Portelli, A.

1989 Historia y memoria: la muerte de Luigi Trastulli. Historia y Fuente Oral, No. 1.

Prada, J y Pesántez, L.

2017 "Satisfacción y motivación en destinos culturales: tipología de los turistas atraídos por el patrimonio inmaterial en cuenca (Ecuador)". Revista Diálogo Andino, № 52, 2017 , pp. 77-91.

Santana, A.

1998 "Patrimonio cultural y turismo: reflexiones y dudas de un anfitrión”. Revista Ciencia y Mar, № 6: 37-41.

Sin autor

2009 "El patrimonio cultural urbano: identidad, memoria y globalización, Andamios". Revista de Investigación Social, Vol. 6, núm. 12: 7-10.

U NES C O, ht t ps://ich.unesco.org/es/ que-es-el-patrimonio-inmaterial-00003.

Valdez, L. M., K. J. Bettcher y J. E. Valdez

2010 "Production of Maize Beer at a Wari Site in the Ayacucho Valley, Peru". Arqueología Iberoamericana, № 5: 23-35.

\section{Notas}

1 Eran contenedores de alcohol, podían llevar hasta 40 litros de aguardiente. El contrabando también fue de gran importancia en la provincia del Azuay, ya que su producción de licor superaba el $60 \%$ de la producción total del país a inicios de los años 30 .
2 En esta línea, de recuperación de la memoria colectiva como parte estratégica de la revitalización de la identidad, se inserta también el caso del Trapiche de Mascarilla, un bien patrimonial de la cultura material afroecuatoriana (Ver, Antón 2019) 
3 Un ejemplo de manifestaciones de reciprocidad, trabajo grupal y comunitario lo tenemos en Ecuador, donde las bebidas funcionan como elemento de unión entre los participantes. Dicho esto, en la fiesta de San Juan se comparten bebidas entre múltiples actores, tomando como espacios diferentes hogares y familias. En este caso, la bebida funciona para armar relaciones políticas, económicas y afirmar una identidad étnica. Por tanto, el no consumir bebidas es considerado un acto esquivo en las relaciones sociales, pues el negarse implica cierto grado de soberbia de la persona, interpretándose como una negación a la comunidad y el trabajo, o simplemente como una actitud de superioridad frente a los demás (Barlett, 1980: 124).

4 UNESCO, https://ich.unesco.org/es/que-es-el-patrimonioinmaterial-00003. Última entrada: 28 de agosto 2017.

5 UNESCO, https://ich.unesco.org/es/que-es-el-patrimonioinmaterial-00003. Última entrada: 28 de agosto 2017.
6 UNESCO, https://ich.unesco.org/es/que-es-el-patrimonioinmaterial-00003. Última entrada: 28 de agosto 2017

$7 \quad$ Registro oficial, Ley Orgánica de Cultura 2016.

$8 \quad$ Ley Orgánica de Cultura del Ecuador.

9 Entrevista a Eloy Cedillo, realizada por Miguel Novillo, abril 2017.

10 Entre los nombres de los intermediarios destacan Juan Eljuri, Pedro Bohorque y Salvador Pacheco.

11 Entrevista a Eloy Cedillo, realizada por Miguel Novillo, abril 2017.

12 http://www.eltelegrafo.com.ec/noticias/regional-sur/1/ en-azuay-se-desarrollo-una-intensa-historia-de-contrabandode-alcohol. Última entrada: 26 de agosto 2017.

13 Entrevista a Víctor Calderón, realizada por Miguel Novillo y Elsa Sinchi, abril 2017. 